\title{
Motivation: A Key Element to Adopt Healthy Habits and Improve Oral Health
}

\author{
Pacheco $\mathrm{KG}^{1}$, Enciso $\mathrm{PA}^{1}$, Martinez Lizan $\mathrm{I}^{2 *}$ and Pareja $\mathrm{G}^{3}$ \\ ${ }^{1}$ Dental postgraduate student, Faculty of Medicine and Health Sciences, University of Barcelona, Spain \\ ${ }^{2}$ Lecturer, Faculty of Medicine and Health Sciences, University of Barcelona, Spain \\ ${ }^{3}$ Clinic, Faculty of Medicine and Health Sciences, University of Barcelona, Spain
}

Submission: September 17, 2019; Published: October 31, 2019

*Corresponding author: Isabel Martinez Lizan, Preventive and Community Dentistry, School of Dentistry, Faculty of Medicine and Health Sciences (University of Barcelona), Campus Bellvitge. Pavello de Govern 2를 planta. C/Feixa Llarga s/n, 08907 L'Hospitalet de Llobregat, Barcelona, Spain

\begin{abstract}
Lack of compliance on patient's recommendations of self-care to prevent oral diseases is a stressful issue for dental practitioners Psychological theories explain how individuals achieve healthy and persistent behaviours throughout life when intrinsic motivation is used.
\end{abstract}

Aim: The aim of this study is to go deeper into intrinsic motivation procedures to improve patient compliance and adherence in dental practice.

Methods: A systematically review about (1) motivation in dentistry, (2) motivational methods and (3) measuring instruments was conducted in three databases: Pubmed, Cochrane Library and Scopus.

Results: A total of 27 articles were included in the review after considering inclusion and exclusion criteria from an initial search of 122 titles. Oral health education and motivational interview are the two motivational methods that have been used the most to date, but only motivational interview works specifically on intrinsic motivation.

Conclusion: Current evidence shows that acquisition of healthy behaviours in patients can be achieved by creating in them the need or internal interest in behaviour change. Dental practitioners should work on the behavioural aspects of patients to obtain conscious and responsible individuals with their own oral health.

Keywords: Health Behaviour; Intrinsic Motivation; Oral Health Education; Motivational Interview; Oral Diseases

Abbreviations: PCC: Patient Centred Care; SDT: Self-determination theory; MI: Motivational Interview; OHE: Oral Health Education; OHI: Oral Hygiene Instructions; OHA: Oral Hygiene Advice; PI: Plaque Index score; RDH: Registered dental hygienist; ECC: Early Childhood Caries; DIM-S: Intrinsic Dental Motivation Scale; DTMS: Motivation Scale in Dental Treatment; TSRQ: Self-Regulation Questionnaire for Dental Treatment.

\section{Introduction}

Patient-Centred Care (PCC) is a new concept in health care to refer the practitioners' approaching of the whole person to understand the patient and implies an enhancement of their relationship. This perspective allows a shared vision between clinician-patient and provide the best preventive, diagnostic and therapeutic strategy based on the best available scientific evidence $[1,2]$. Being patient- centred doesn't mean that professionals in charge of care leave all control to the patient but it's in accordance with the recommendations of experts in health. In 2010 at the 7th WHO World Conference on Health Promotion, five key issues are published to address the main strategic areas of health, these are community empowerment, literacy and health behaviour, strengthening of systems health, association and intersectoral action and capacity development for health promotion [3].
Most chronic dental diseases could be prevented by adopting effective preventive behaviours such as: regular oral hygiene, the use of fluoride toothpaste, reduced sugar intake and smoking cessation. Control and management of tooth decay and periodontal disease depend largely on daily self-care and compliance of preventive and curative measures [4-7].

Health-related behaviour is understood as the way in which people act to stay healthy and thereby avoid illness and disability [8]. In framework of dental care, oral health behaviour is reflected in the prevention carried out by patients, that is, in compliance with the recommendations of good oral hygiene, nutritional and self-care habits. The reasons why patients do not adhere to this behaviour can be diverse: socioeconomic level, self-esteem, fear, lack of relevant education and / or unpleasant experiences [9]. 
Motivation is defined as the revitalization of behaviour to achieve a goal. There is a wide variety of studies that have applied this concept to achieve behavioural changes in health [10-12]. Due to the positive outcomes, motivation is specifically valuable in those areas where a person mobilizes the actions of others: manager, teacher, coach, health care provider or parents, for instance. People are moved to act by very different factors; they may be motivated to carry out an activity because they internally value it or, on the contrary, they carry out the activity because there is a strong external coercion. Individuals can be urged into action for a permanent interest, a sense of personal commitment or antagonistically for a bribe, for fear of being monitored or for obtaining a reward. There are several theories that explain the types of motivation and specifically the impact they have on healthy behaviours [13]. The theory of self-determination (SDT) has been responsible for explaining what type of motivation is exhibited at a given time, the SDT classifies motivation as intrinsic and extrinsic, and each has specific consequences for learning, performance, personal experience and general well-being [13].

Flórez \& Castellanos [12] also raise two types of motivation; autonomous motivation (intrinsic) and controlled motivation(extrinsic). The first is based on very internal identifications and incorporates behaviours to personal values with a sense of will, freedom and choice - which would be the case from a drug user who decides to seek professional help because "he believes that seeking help is consistent with the personal value of trying his best to live a drug-free lifestyle"-. The opposite of autonomous motivation is controlled or extrinsic motivation, in which a person acts to please or impose the surrounding environment; for instance, a drug user who accepts the treatment because he adheres to the control of his parents. Due to the autonomous motivation is an activity that will be more stable and with a longer duration, it`s argued that it has positive effects in health environment as well as alcohol and tobacco consumers, people with obesity, diabetes, persistent medication adherence and finally to improve self-care [12].

People who perform an intrinsically motivated action or activity will have more interest, enthusiasm and confidence, which in turn manifests itself as greater performance, persistence, creativity, self-esteem, and general well-being [13,14]. Extrinsic motivation contrasts with intrinsic motivation. Extrinsically motivated behaviours are the least autonomous and are known as externally regulated. External regulation (extrinsic motivation) of dental behaviours involves participating in the event in order to achieve desired tangible rewards or to avoid more severe punishment, some examples are visiting the dental clinic to avoid criticism of the dentist, obtaining a reward, avoid the inconvenience of others or avoid painful dental treatment in the future. Externally regulated dental treatment behaviours are controlled by the surrounding environment and therefore are not self-determined $[13,14]$.
Interesting research has been done on the types of motivation and their importance in health care environment. Specifically in oral health, in 1994, Syrjälä et al. [15] state that people who are intrinsically motivated with regard to dental care are interested in caring for their teeth to preserve them for as long as possible and consider factors such as the healthy diet for their dental health. On the other hand, people with extrinsic motivation have no interest in caring for their teeth, prefer dental extraction and emergency treatment in addition; they brush their teeth not for internal satisfaction but for pleasing other people and their diet is high in carbohydrates, increasing the risk factors for oral and systemic diseases [15]. Regarding the effects of being extrinsically motivated (external regulation) in dental treatment, we know that a person's adherence to oral self-care behaviour is based on incentives or rewards, such behaviour will be short-lived and will not persist when the person is no longer being supervised or rewarded [16].

As described above, to perform an activity, motivation must be present, either intrinsically or extrinsically. In oral environment, the long-term persistence of adequate hygienic habits is the key to oral health, and that is the reason because practitioners must achieve intrinsic motivation in patients better than influenced them by external agents. The theory of cognitive evaluation CET (sub-theory within the theory of self-determination) explains that there are several factors that have to be present for intrinsic motivation to be established in an individual, these factors are known as "innate psychological needs" which are: competition, autonomy and social relationship [13].

Dentist behaviours could facilitate the satisfaction of basic psychological needs of people when they attend to dental settings. The link between patient-doctor can satisfy the need for patients' social relationship when there is empathy, moral support, friendship and an informal relationship. The patient's participation in treatment planning before it is implemented can increase your internal experience of choice and meet your need for autonomy. Finally, an effective communication between the dentist and the patient about what and why is going to be done allow the patient to feel more involved, which will lead him to accept the process and help to meet his need for competence [1517].

Nowadays, patients' adherence to oral hygiene habits is a challenging objective. Motivating patients to adhere to dental therapies and correct hygienic habits has traditionally been based on informing the patient about the existence of their disease and the compliance of clinician recommendations. In some cases, that recommendations could be accompanied using scare tactics such as 'the loss of teeth if you do not carry out the treatment' or the deterioration of the dental treatments if it is not provided correct oral hygiene. Nevertheless, some scientific evidence indicates that patients are generally not motivated by these methods and affect motivation in the opposite way [18]. 
Prevention is the key to the success of any dental treatment. If patients are not motivated, they will not be committed to oral care, so the failure of a treatment is inevitable. Adherence to an oral hygiene regimen is important if professionals who provide oral care and desire a greater proportion of people retain their teeth for much longer.

There is a great need in dentistry for effective interventions to improve patient compliance with oral hygiene habits [9]. As the current evidence shows, many impediments reduce healthy behaviours. It is proven that dentists can play an important role in ensuring that patients acquire a commitment to their oral health through motivational reinforcements; that help to integrate extrinsic behaviour into intrinsic motivation. The aim of this review is to inform health professionals about the methods and strategies available to use motivation as another tool in the prevention and maintenance of the patient's oral health.

\section{Methodology}

A systematic search strategy was developed. The age range used for the inclusion of articles was from 2002 to date.

\section{Description of the search strategy}

For PubMed database, the MeSH descriptor was used with the following terminology: (motivation and dental caries), (motivational interview and dentistry), (education, oral hygiene and motivation) and following filters: studies made in humans from 2002 to the present. A search was also carried out in the Cochrane library using the terminology mentioned above. We conclude the electronic search in the Scopus database, not finding bibliography on the subject. Additionally, hand-searching was made and relevant texts such as WHO documents, and book chapters were also screened.

Given the wide variety of different studies on this subject area, it was considered appropriate to adopt broad inclusion/exclusion criteria as explained below.

\section{Inclusion criteria}

Full-text articles in English, Spanish and 1 Portugueselanguage articles; all kinds of research carried out in the different age groups; studies of motivation in dentistry, as well as concepts, bases, enhancers and measuring instruments of this subject. There were also integrated studies that reported methods to motivate patients in dental setting, specifically interventions based on oral health education and motivational interview (MI). It was decided also to incorporate studies whose interventions were addressed to achieve, at least, one healthy behaviour: visits to the dentist, proper tooth brushing, use of dental adjuvants...

\section{Exclusion criteria}

Articles that were not English or Spanish language were excluded; studies that used other motivational methods such as visual stimuli, text messages and / or telephone interventions were also ruled out. In the case of motivational interviews (MI), articles were excluded whose intervention was not aimed at changing inappropriate oral habits, for example: MI in epileptic, diabetic patients, patients with risk behaviours to contract HIV and other diseases.

\section{Results}

\section{Search Results}

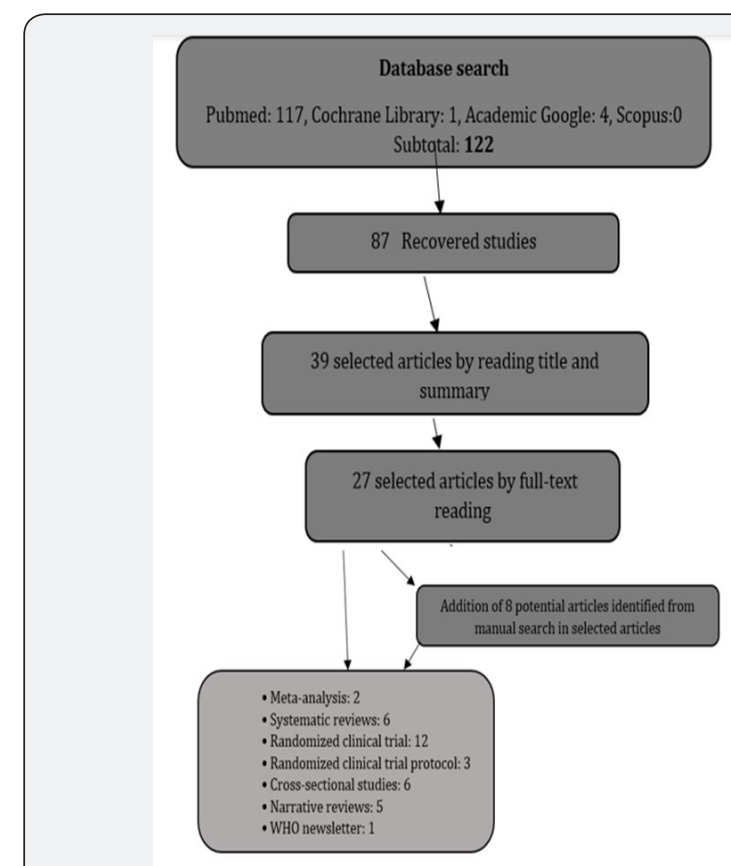

Figure 1: Flow of articles through the literature review process.

The searches in the databases resulted in a total of 122 articles, which became 39 articles after reading the corresponding titles and abstracts; finally, 27 articles were considered to be eligible for inclusion in the review (Figure 1). From the combination of electronic and manual search strategies, a reference list of the most relevant studies in motivation is presented in Table 1.

Table 1: Key references on motivation and oral health.

\begin{tabular}{|c|c|c|c|c|c|c|}
\hline $\mathbf{N}$ & $\begin{array}{l}\text { Author (s) } \\
\text { Year }\end{array}$ & Study Title & Type of Study & Study Population & $\begin{array}{l}\text { Motivational } \\
\text { Intervention }\end{array}$ & Results \\
\hline 1 & $\begin{array}{l}\text { Ceriotti et } \\
\text { al. (2002) }\end{array}$ & $\begin{array}{l}\text { Motivation on } \\
\text { plaque control and } \\
\text { gingival bleeding } \\
\text { in school children }\end{array}$ & $\begin{array}{l}\text { Randomized } \\
\text { clinical trial }\end{array}$ & $\begin{array}{l}\text { Preschool students } \\
5-14 \text { years }\end{array}$ & $\begin{array}{l}\text { Oral health } \\
\text { education }\end{array}$ & $\begin{array}{l}\text { Authors emphasize motivational intervention } \\
\text { through oral health education to reduce and } \\
\text { control the rate of gingival bleeding and dental } \\
\text { biofilm. MI is much more effective if accompanied } \\
\text { by continuous reinforcement sessions. }\end{array}$ \\
\hline
\end{tabular}




\section{Psychology and Behavioral Science International Journal}

\begin{tabular}{|c|c|c|c|c|c|c|}
\hline 2 & $\begin{array}{l}\text { Weinstein } \\
\text { et al. } \\
(2004)\end{array}$ & $\begin{array}{l}\text { Motivating parents } \\
\text { to prevent caries } \\
\text { in their young } \\
\text { children one year } \\
\text { findings }\end{array}$ & $\begin{array}{l}\text { Randomized } \\
\text { clinical trial }\end{array}$ & $\begin{array}{l}\text { Parents of children } \\
\text { 6-18 months }\end{array}$ & $\begin{array}{l}\text { Oral health } \\
\text { education and } \\
\text { motivational } \\
\text { interview }\end{array}$ & $\begin{array}{l}\text { At the end of the study, children in the } \\
\text { experimental group (received motivational } \\
\text { interview and traditional education for oral } \\
\text { health) presented } 0.71 \text { carious surfaces, while } \\
\text { presented } 1.91 \text { carious surfaces. children in the } \\
\text { control group (received traditional education in } \\
\text { oral health) }\end{array}$ \\
\hline 3 & $\begin{array}{l}\text { Zuhal } \\
\text { Yetkin et } \\
\text { al. (2007) }\end{array}$ & $\begin{array}{l}\text { Appropriate } \\
\text { oral hygiene } \\
\text { motivation method } \\
\text { for patients with } \\
\text { fixed appliances }\end{array}$ & $\begin{array}{l}\text { Randomized } \\
\text { clinical trial }\end{array}$ & Young $15-16$ years & $\begin{array}{l}\text { Oral health } \\
\text { education }\end{array}$ & $\begin{array}{l}\text { Verbal information through the catalog of } \\
\text { illustrations and self-application by the patient } \\
\text { was more effective in removing dental plaque } \\
\text { and reducing gingival index scores compared to } \\
\text { other motivation methods based on oral health } \\
\text { education. }\end{array}$ \\
\hline 4 & $\begin{array}{l}\text { Petersen et } \\
\text { al. (2009) }\end{array}$ & $\begin{array}{l}\text { The 7th Who } \\
\text { global conference } \\
\text { on health } \\
\text { promotion } \\
\text { - towards } \\
\text { integration of oral } \\
\text { health }\end{array}$ & Report & $\begin{array}{l}\text { Adults and } \\
\text { Children }\end{array}$ & $\begin{array}{l}\text { Oral health } \\
\text { education }\end{array}$ & $\begin{array}{l}\text { Five key issues are published to address the } \\
\text { main strategic areas of health: (1)Community } \\
\text { empowerment, (2)Literacy and health behavior, } \\
\text { (3)Strengthening of health systems, (4) } \\
\text { Association and intersectoral action and (5) } \\
\text { capacity building for the promotion of health }\end{array}$ \\
\hline 5 & $\begin{array}{l}\text { Stenman et } \\
\text { al. (2012) }\end{array}$ & $\begin{array}{l}\text { A single session } \\
\text { of motivational } \\
\text { interviewing } \\
\text { as an additive } \\
\text { means to improve } \\
\text { adherence in } \\
\text { periodontal } \\
\text { infection control. }\end{array}$ & $\begin{array}{l}\text { Randomized } \\
\text { clinical trial }\end{array}$ & Adults $48-51$ years & $\begin{array}{l}\text { Comparison of } \\
\text { motivational } \\
\text { interview and } \\
\text { oral health } \\
\text { education }\end{array}$ & $\begin{array}{l}\text { This study revealed no superior positive effects } \\
\text { when applying a single motivational interview } \\
\text { session. both, test group (motivational interview } \\
\text { plus oral health education) and the control group } \\
\text { (oral health education) showed improvements }\end{array}$ \\
\hline 6 & $\begin{array}{l}\text { Flórez et } \\
\text { al. (2012) }\end{array}$ & $\begin{array}{c}\text { Efectos de } \\
\text { la entrevista } \\
\text { motivacional sobre } \\
\text { la motivación } \\
\text { autónoma } \\
\text { en jóvenes } \\
\text { consumidores de } \\
\text { alcohol }\end{array}$ & $\begin{array}{l}\text { Randomized } \\
\text { clinical trial }\end{array}$ & Teens 13-18 years & $\begin{array}{l}\text { Motivational } \\
\text { interview }\end{array}$ & $\begin{array}{l}\text { The study showed that autonomous motivation } \\
\text { increased significantly in the experimental group } \\
\text { (received MI) when the results were compared } \\
\text { intragroup but did not reach levels of statistical } \\
\text { significance. However, the results with respect } \\
\text { to controlled motivation showed a significant } \\
\text { increase. }\end{array}$ \\
\hline 7 & $\begin{array}{l}\text { Brand et al. } \\
\quad(2012)\end{array}$ & $\begin{array}{c}\text { Impact of } \\
\text { single-session } \\
\text { motivational } \\
\text { interviewing on } \\
\text { clinical outcomes } \\
\text { following } \\
\text { periodontal } \\
\text { maintenance } \\
\text { therapy }\end{array}$ & $\begin{array}{l}\text { Randomized } \\
\text { clinical trial }\end{array}$ & Adults $61-62$ years & $\begin{array}{l}\text { Comparison } \\
\text { between } \\
\text { oral health } \\
\text { education and } \\
\text { motivational } \\
\text { interview }\end{array}$ & $\begin{array}{l}\text { There were no significant differences between the } \\
\text { groups }\end{array}$ \\
\hline 8 & $\begin{array}{l}\text { López et al. } \\
\text { (2012) }\end{array}$ & $\begin{array}{l}\text { Effectiveness of } \\
\text { a motivational- } \\
\text { behavioural skills } \\
\text { protocol for oral } \\
\text { hygiene among } \\
\text { patients with } \\
\text { hyposalivation }\end{array}$ & $\begin{array}{l}\text { Randomized } \\
\text { clinical trial }\end{array}$ & Adults $31-84$ years & $\begin{array}{l}\text { Comparison } \\
\text { between } \\
\text { oral health } \\
\text { education and } \\
\text { motivational } \\
\text { interview }\end{array}$ & $\begin{array}{l}\text { Patients in both groups had significantly lower } \\
\text { plaque rates, bleeding rates and reduced depth } \\
\text { of probing but the use of interproximal brushing } \\
\text { were higher in the group that received the } \\
\text { motivational interview }\end{array}$ \\
\hline 9 & $\begin{array}{l}\text { Ismail et al. } \\
\quad(2011)\end{array}$ & $\begin{array}{l}\text { Evaluation of a } \\
\text { brief tailored } \\
\text { motivational } \\
\text { intervention to } \\
\text { prevent early } \\
\text { childhood caries }\end{array}$ & $\begin{array}{l}\text { Randomized } \\
\text { clinical trial }\end{array}$ & $\begin{array}{l}\text { Parents of children } \\
0-5 \text { years }\end{array}$ & $\begin{array}{l}\text { Oral health } \\
\text { education and } \\
\text { motivational } \\
\text { interview }\end{array}$ & $\begin{array}{l}\text { A single motivational interview intervention could } \\
\text { change some oral health behaviors but failed } \\
\text { to reduce the amount of new untreated carious } \\
\text { lesions. }\end{array}$ \\
\hline 10 & $\begin{array}{l}\text { Godard et } \\
\text { al. (2011) }\end{array}$ & $\begin{array}{l}\text { Application of self- } \\
\text { regulation theory } \\
\text { and motivational } \\
\text { interview for } \\
\text { improving oral } \\
\text { hygiene }\end{array}$ & $\begin{array}{l}\text { Randomized } \\
\text { clinical trial }\end{array}$ & Adults: $48-51$ years & $\begin{array}{l}\text { Motivation } \\
\text { interview and } \\
\text { oral health } \\
\text { education }\end{array}$ & $\begin{array}{l}\text { The experimental group (motivational interview } \\
\text { plus oral hygiene instructions) showed a } \\
\text { significantly greater decrease in plaque index } \\
\text { than the control group (received only oral hygiene } \\
\text { instructions). }\end{array}$ \\
\hline
\end{tabular}




\section{Psychology and Behavioral Science International Journal}

\begin{tabular}{|c|c|c|c|c|c|c|}
\hline 11 & $\begin{array}{l}\text { Menegaz et } \\
\text { al. (2018) }\end{array}$ & $\begin{array}{l}\text { Educational } \\
\text { interventions in } \\
\text { health services } \\
\text { and oral health: } \\
\text { systematic review }\end{array}$ & $\begin{array}{l}\text { Systematic } \\
\text { review }\end{array}$ & Adults and children & $\begin{array}{l}\text { Oral health } \\
\text { education }\end{array}$ & $\begin{array}{l}\text { Educational interventions with more than one } \\
\text { associated method (video session, printed booklet } \\
\text { with guidelines, verbal guidance and brushing } \\
\text { practices) showed significant improvements in } \\
\text { dental caries reduction. }\end{array}$ \\
\hline 12 & $\begin{array}{c}\text { Naidu et al. } \\
\text { (2015) }\end{array}$ & $\begin{array}{l}\text { The effect of } \\
\text { motivational } \\
\text { interviewing on } \\
\text { oral healthcare } \\
\text { knowledge, } \\
\text { attitudes and } \\
\text { behaviour of } \\
\text { parents and } \\
\text { caregivers of } \\
\text { preschool children }\end{array}$ & $\begin{array}{l}\text { Randomized } \\
\text { clinical trial }\end{array}$ & Adults & $\begin{array}{l}\text { Comparison } \\
\text { of motivation } \\
\text { interview and } \\
\text { oral health } \\
\text { education }\end{array}$ & $\begin{array}{l}\text { Participants who received a motivational } \\
\text { interview showed better knowledge in a wider } \\
\text { range of aspects (correct amount of toothpaste, } \\
\text { supervised brushing position, fluoride varnish } \\
\text { and the safest time to consume sugary foods } \\
\text { and drinks) compared to those who received } \\
\text { traditional education in oral health. }\end{array}$ \\
\hline
\end{tabular}

Motivational methods to promote oral hygiene habits in-patient

Oral Health Education, Oral Hygiene Instructions or Oral Hygiene Advice: Patients could be motivated and change their undesirable habits through helping them to understand the process of their disease, its consequences and the preventive actions required. Thus, they will reduce their risk of oral diseases [19]. WHO defined Health Education as any combination of information and education activities in order to make people aware of how to achieve health and seek help when they need it One of the objectives of the health education is to modify insane habits and behaviours [20]. In many studies Oral Health Education (OHE) is used as a method to motivate patients in this aspect; that is Oral Hygiene Instructions (OHI) or/and Oral Hygiene Advice (OHA).

\section{Usually they implement the strategies:}

i. Educational lectures or conferences on the development of the dental biofilm,

ii. Guidance on brushing techniques, flossing or interdental brushes,

iii. Tips on the use of fluoride toothpaste,

iv. Education through catalogues, videos, photographs,

v. Specific hygiene tips for patients using fixed / removable dentures and braces.

Evidence is greater when provided to patients by members of the dental team can motivate them to perform healthy oral habits. In a study on the effectiveness of several sessions of oral health education used as a motivation method, Ceriotti \& Cauhy [21] applied this intervention in students aged 5-14. This consisted: educational conference on the development of dental biofilm, guidance on the technique of brushing and flossing both directly and through the help of demonstrative macro models. The students were divided into 2 groups; group A (motivated in one session) and group B (motivated in four sessions). In the results obtained it was observed that in the 74 students of group B there was a $100 \%$ reduction in the index of visible plaque at final examinations. Only $45.9 \%$ of the students in group A reduced values. As a conclusion authors noted the importance of continuous reinforcement sessions to improve the control of the dental biofilm [21].

The orthodontic treatment with fixed devices alters the oral environment, increases the amount of plaque, changes the composition of the flora and complicates the cleaning of the patient. Definitely, patients were orthodontic treatments suffer high risk of various oral pathologies: periodontal pockets, white spot lesions, decalcifications and cavity formation. So, the removal of dental plaque is essential to prevent the diseases listed above and OHE and OHI have been used to motivate patients with orthodontic treatment with the goal of maintaining your oral health. Zuhal Yetkin et al. [22] conducted a study in patients of 15-16 patients with orthodontic appliances to determine and compare the effectiveness of the most appropriate motivational methods to promote oral hygiene. The participants were divided into 5 groups according to the method used: (I) verbal information; (II) verbal information with model demonstration; (III) verbal information with model demonstration and self-application under the supervision of the dentist; (IV) verbal information through the catalogue of illustrations and the last group and (V) verbal information through the catalogue of illustrations and self-application of the patient under supervision. As a result, all periodontal parameters improved significantly after 4 weeks in all group. In addition, verbal information through the catalogue of illustrations and self-application were the most effective motivational methods in the removal of plaque and decrease indicators of periodontal diseases [22].

Previous results on the effectiveness of OHE and $\mathrm{OHI}$ as motivational methods coincide with the study by Marini et al who investigated the effects on plaque control using a manual or electric toothbrush, with or without repeated hygiene instructions oral and motivation in patients using fixed orthodontic appliances. Participants were divided into 4 groups (E1, E2, M1, M2) which received oral hygiene instruction (OHI) and motivation by a registered dental hygienist (RDH). The groups (E1, E2) received an electric toothbrush and the other 2 groups (M1, M2) a manual toothbrush. The OHI consisted of explanation about correct use of the electric brush in E1 and E2; and effective technique with manual brush to M1 and M2 groups. All participants were given an illustrated brochure summarizing 
the OHI. The motivation for oral hygiene (based on OHE) was carried out by RDH. OHE and repeated OHI were performed in groups E1, M1. The results showed that the improvement in the plaque index score (PI) decreased significantly over time in all groups, but in groups E1 and M1 reduction in the PI score was significantly greater compared to the other groups. The authors suggest that $\mathrm{OHI}$ and repeated motivation are crucial in reducing the PI score over time regardless of whether patients use manual or electric toothbrushes [23]. Recently Jing Huang et al conducted a systematic review and meta-analysis regarding ways to achieve motivation in oral hygiene in patients with orthodontic treatment The authors concluded that modified oral hygiene instruction $(\mathrm{OHI})$ next to the setting office was the most widely used method to improve motivation among orthodontic patients. The modified $\mathrm{OHI}$ included verbal and written information, photos or catalogues, videos and visual demonstrations with models or experimental equipment to explain the composition and mechanism of dental plaque formation. Authors recommended that motivation can be applied not only to orthodontic patients but also to patients with periodontal diseases or implant plans that would likely have multiple visits to dentists and a long duration of treatment [24].

\section{Motivational Interview}

Oral health education is focused on spreading information and giving normative advice. Nevertheless, even though patient knowledge can improve, such knowledge gain does not translate into sustained changes in their oral health behaviours. Providing oral health education in the dental settings is usually an open persuasion exercise that seems to be a convincing line of reasoning for the dental staff but falls on not listening or results in the resistance of patients to change [5].

Threats to personal freedom, for example when a patient is told "what to do", causes a corresponding increase in their attempts to maintain independence (resist, rationalize existing behaviour, admit verbally without the intention of doing so). Nowadays, patients know the risks of tobacco, systemic diseases and other conditions on oral health. However, eliminating harmful habits and establishing protective habits is easier said than done and health education does not seem to be enough. The absence or ineffectiveness of educational interventions for the prevention of oral diseases may be because the determinants of human behaviour are not considered $[25,26]$.

Motivational interviewing (MI) is a counselling technique considered highly effective in addiction disorders that has been adapted according to the objectives pursued and used to achieve behavioural changes in different areas of health. MI uses cognitive behavioural techniques that are aimed at achieving a change in customer behaviour. MI causes internal motivations in customers and improves their willingness to change. This customer-Centred approach contrasts with traditional health education and counselling where professionals are the most active participants in presenting problems and offering solutions, while customers are normally excluded from the definition of problems. and decision making. MI uses techniques that causes self-motivated statements and respects the autonomy of the individual, putting the responsibility for change directly under the control of the customer. When MI is performed effectively the likelihood of the individual becoming involved in a behaviour change increases [22-29]. Below, we show a brief description of steps of the motivational interview adapted for the application in the dental setting:

\section{Establish a Professional-Patient Relationship (Empathy)}

Working together with the same contribution of patient and staff and respecting the patient's autonomy is the first step to establish a relationship of trust between them. It is important to show empathy from the beginning to support a collaborative approach to behaviour change. This includes listening reflexively, understanding what is happening to the patient and giving space to express their perspective. Then the agenda is established and explained and discussed in the consultation as part of the session planning.

\section{Identify the objective behaviour (Focus)}

This step will help to identify "what to change". The objective is to get the patients to recognize in what state they are and where they want to get, that is, to achieve the importance of change from the customer perspective. The focus is the process by which the health professional in collaboration with the patient develops and maintains a specific direction in the conversation about the change. To start the conversation, we will ask some questions.

Examples could include:

i. Would you like to talk about quitting smoking to improve your periodontal health?

ii. It seems you're worried about bleeding your gums today. Would you like to discuss this now?

iii. Should we try to find out what causes gum bleeding?

\section{Identify Intrinsic motivation to change (Evoking)}

At this stage we'll let space to the patient to express their own ideas and plans for behaviour change. We try to make the patient understand that he has many knowledge and skills that only need to be evoked and driven to achieve change. So, we'll start by measuring the knowledge and understanding of the patients. The clinician's role is primarily fill in the gaps and provide relevant information upon request of permission to the patient. In this way it is not perceived as "telling them what to do".

Examples may include: You seem to have a good awareness of how tobacco affects the health of your gums. Would it be nice to tell you more about this? there are a couple of comments I could make ...

On this step it is common for the patient to express resistance to change (discuss, interrupt, blame others). Maybe the patient refuses to accept the offer to exchange information at the initial 
appointment, He/she may not be ready. In that case, we can ask the patient if he/she would you like us to talk about this at the next appointment. If, on the contrary, the patient agrees to receive the information, we will listen carefully in order to capture changes in the conversation. The talk of change is defined as the statements of the patients about their wishes or needs to change. The role of the clinician will be to highlight the pros and cons of the patient's oral hygiene behaviours and should evoke the patient the reasons for any change proposed and the risks of not changing it. It is important at this stage to reduce the probability of misunderstanding what the patient is expressing to the clinician, that is, to make a thoughtful listening. This can be achieved by paraphrasing, repeating and reflecting the patient's feelings and thoughts. For example: it seems that you would like to quit smoking, but you cannot at this stage since you are very stressed. Is that correct?

\section{Patient Planning (self-efficacy)}

This step let the patient to develop their own confidence to obtain the ability to change and find solutions to deal with obstacles, as well as to develop realistic and attainable strategies necessary for behaviour change. The goal is for the patient to commit to change instead of the clinician telling him how to change. Therefore, the patient has to believe in his own argument for change, which in turn will increase the likelihood of a change in behaviour. An example of the questions that can be asked at this stage: Is there anything I can help you with? "What is the first step you would like to take?" It is important to carry out follow-up visits to evaluate changes. We must recognize and congratulate for any attempt to change behaviour, thereby achieving self-efficacy and patient confidence. Any errors or failures should be reviewed trying to explore the reasons that caused it $[25,27,30,31]$.

The application of the 4 principles of the motivational interview is summarized in listening and understanding the patient: specifically knowing the reasons why a change in behaviour is difficult for him and making him feel that he is not being judged, on the contrary, helping him to make the decisions he prefers, so the professional's role is focused on letting the patients to be active participants in the definition of the problem and offering solutions. This is the key point of the motivational interview that contrasts with the conventional motivational methods in oral health $[25,32]$. MI is a motivational method currently becoming very popular. In most of the research conducted on MI for acquisition of healthy oral behaviours it has been compared its effectiveness with conventional oral health education. The following describes a series of studies carried out in different population groups, in which the motivational interview has been used to achieve a change in oral health behaviour.

\section{Motivational Interview to prevent Early Childhood Caries}

Early Childhood Caries (ECC) is the term used for dental caries in children, which occurs after the eruption of deciduous teeth. ECC can be a painful condition that influences the ability of the child to eat properly, sleep through the night, grow, develop normally and therefore reach their full potential. In addition, caries in primary teeth has a significant and positive association with tooth decay and permanent tooth malposition. Most ECC prevention strategies require parents to change existing behaviours, for example: bottle feeding; or adopt new behaviours: brushing regularly, interdental hygiene etc. $[28,30,33]$.

Since early childhood is a critical stage in providing oral health habits, this period offers a unique opportunity for behavioural interventions. Cultivating healthy dental habits in preschoolaged children whose permanent teeth will erupt later would increase the chances of permanent tooth free of decay. Children whose mothers show a lack of knowledge about oral health and the means of prevention of the ECC have a higher prevalence and severity of caries than those whose mothers have such knowledge. However, the simple fact of knowing about good oral habits often it is insufficient to change unhealthy behaviours $[28,30]$.

Behavioural interventions performed in childhood are promising and can have successful results. At this stage we can prevent and address several risk factors for tooth decay since both dietary and dental hygiene habits are barely being implemented. Moreover, we often have the support of parents receptive to health messages during this period. Is through the motivation and training of parents that the appropriate model will be followed so that their children will acquire and achieve healthy behaviours. So far, parents' knowledge, beliefs, attitudes and behaviours about oral health could have a positive or negative impact on the oral health of infants [28,34].

Weinstein et al. [25] conducted a study in parents of 240 children aged 6-18 months with a high risk of dental caries with the aim of comparing the effect of an MI intervention with that of traditional health education. Parents in the control group received a brochure and watched a video. Parents in the intervention group received an MI counselling session, received the brochure and watched the video. After one year, the carious surfaces were compared in both groups. It was found that children in the intervention group had 0.71 carious surfaces while those in the control group had 1.91 carious surfaces [25].

The effectiveness of MI in improving oral health behaviours has also been evaluated by Ismail et al. [30] who used a brief motivational interview to promote healthy behaviours (brushing, non-cariogenic food selection, pre-cavity control, consultations with the dentist). The study was conducted in parents of 0-5-year-old African American children, who were divided into two groups. The intervention group received the motivational interview (MI) and watched a 15-minute video on "how parents can keep their caries-free children?". Participants of this group received reinforcement calls within 6 months of the intervention. Participants of the second group only watched the educational video. After 6 months of follow-up, the parents who received $\mathrm{MI}+$ video obtained a higher score on the frequency of some behaviours such as be sure that their children brushed at bedtime. 
After two years it was found that these same parents still followed the behaviours before mentioned but no greater frequency was found in brushing children at least twice a day. In addition to this, in the final evaluation the children whose parents received the MI did not have fewer "untreated carious lesions". Authors conclude that with a single motivational interviewing intervention only managed to change some behaviours in oral health [30].

Previous results were similar to those obtained by Naidu et al. [34] on the effect of MI in contrast to traditional oral health education on knowledge, attitudes, beliefs and behaviours between parents and caregivers in children. preschool age. Control group received a 30-minute talk about children's dental care, including advice on diet, oral hygiene, fluoride use and dental assistance. At the end, participants received a take-home booklet containing information on oral health. On the other hand, participants in the intervention group received a 30-minute session based on an MI approach and follow-up through telephone contact at two weeks and one month in order to reinforce the commitment and provide support to participants also provided with the same oral health information booklet. The results obtained were as follows: at 4 months of follow-up, there was a significant increase in the frequency of weekly brushing of children in the intervention group compared with control group; the majority of participants tried to implement some changes in practices of oral health for their children such as brushing teeth twice a day, changing the position of the brush (correct form) and use of fluoride toothpaste. In addition , they found that some of the participants had children that keep on using the bottle (mainly at night) and that although they expressed difficulties to change this behaviour in the past, after the intervention of MI they made new efforts to interrupt this practice [34].

\section{Motivational Interview in adolescents, youth and adults}

Dental caries has profound impacts on the physical, psychological and social well-being of adolescents. Tooth decay can be prevented if healthy personal care behaviours are adopted. Early adolescence is a socially critical period in which health behaviours will become perpetual life habits. This stage creates a unique opportunity for oral health interventions to positively alter unfavourable behaviours. Adolescents are not oriented to the future and don't consider themselves vulnerable to health problems. Alerting them to the consequences of unhealthy habits has little impact on their health behaviours. In addition, with their growing demand for autonomy, direct counselling often results in resistance as they feel that their own thoughts, feelings or decisions are interfered with [26].

In order to know the effectiveness of the motivational interview compared to oral health education to promote positive changes, $\mathrm{Wu}$ et al. [26] conducted a study in adolescents receiving: (I) Education for health (oral health talk and educational brochures), (II) Motivational interview, (III) Motivational interview plus a educational program based in caries risk assessment. The results of the study showed that groups receiving motivational interview showed a high improvement in the proper behaviours of oral health and a smaller increase in dental caries compared to the group that only received oral health education [26]. In addition to the need to apply MI in patients to achieve a change in behaviour, it may be necessary for health professionals too, to be motivated through an MI session as argued by Woelber et al. [35] in their study, where provided an MI workshop taught to dental students with the aim of improving patient adherence to professional recommendations. According to the results of the study, the periodontal parameters of depth and bleeding at probing and the level of clinical insertion improved in both groups. The group of patients that was attended by students who received the teaching of MI presented a significant improvement in the self-efficacy of interdental cleanliness compared to patients treated by the control group of untrained students [35].

Godard et al. [9] evaluated the effect of a single MI session on oral hygienic habits in patients with periodontitis. Plaque index (PI) was used as an outcome measure to control the practice of daily oral hygiene. In the control group, the patients received oral hygiene instructions that included teaching oral self-care measures (brushing, flossing with the help of a model, as well as a demonstration in the mouth using a facial mirror). Patients received too an illustrated brochure of information about periodontal disease. In the experimental group, patients received MI with a duration of 15-20 min during which the patient was also given information and instructions on oral hygiene. The results of the study indicated that the experimental group showed a significant decrease in plaque index compared to the control group. The authors highlight the importance of the evaluation of patient behaviour and recommend the incorporation of MI into the periodontal treatment plan [9].

In contrast to the results of the previous study, Brand et al. [18] also used a brief session of MI (15-20 min) in adult patients who presented periodontal disease with the objective of obtaining the internal (intrinsic) motivation of the patient and achieving thereby improving plaque control in the home and adherence to periodontal maintenance. The authors reported that the application of MI in the intervention group did not show any relevant effect on intrinsic motivation. In addition, there were no differences between the groups for plaque index, bleeding and depth of probing scores [18].

Non-significant results of MI are also reported in the study by Stenman et al. [36] who determined the potential of a single session of MI in adult patients with periodontal disease with the aim of improving the control of the disease. Participants were divided into 2 groups. The control group received conventional oral health education that consisted of information on periodontal disease, oral hygiene instructions and supra and subgingival mechanical debridement. The subjects in the test group received a single session of MI, the same oral health education as the control group and the corresponding periodontal treatment. Results showed 
improvement in plaque scores and bleeding at probing after the first educational intervention session in both groups. In that case, MI showed no superior effects with respect to conventional education [36]. In summary, some research shows positive effects of the motivational interview on behavioural changes but on the other hand, others found not satisfactory results. Table 2 shows the most recent systematic reviews about this psychological intervention applied in dentistry.

Table 2: Recent systematic reviews on the role of the motivational interview in oral health.

\begin{tabular}{|c|c|c|c|c|}
\hline $\mathrm{N}$ & Author (s) Year & Study Title & The Purpose of the Study & Results \\
\hline 1 & Cascas et al (2014) & $\begin{array}{l}\text { Effectiveness of } \\
\text { motivational interviewing } \\
\text { at improving oral } \\
\text { health: A systematic review }\end{array}$ & $\begin{array}{l}\text { Analyze the effectiveness of the } \\
\text { motivational } \\
\text { interview to improve oral } \\
\text { health behaviors. }\end{array}$ & $\begin{array}{l}\text { The authors reported contradictory evidence of the } \\
\text { effectiveness of motivational interviews to } \\
\text { improve oral health behaviors. }\end{array}$ \\
\hline \multirow[b]{2}{*}{2} & \multirow[b]{2}{*}{ Gao et al (2014) } & \multirow{2}{*}{$\begin{array}{l}\text { Motivational Interviewing } \\
\text { in } \\
\text { Improving Oral Health }\end{array}$} & \multirow{2}{*}{$\begin{array}{l}\text { Evaluate the effectiveness of } \\
\text { the motivational } \\
\text { interview (MI) compared to } \\
\text { conventional oral } \\
\text { health education (CE) to } \\
\text { improve oral health }\end{array}$} & $\begin{array}{l}\text { Most studies demonstrated the superiority of MI } \\
\text { with respect to the CE to improve at least one clinical } \\
\text { results (plaque index, gingival index, bleeding at } \\
\text { probing, depth at probing), except in two trials in } \\
\text { which the CE was greater than MI. }\end{array}$ \\
\hline & & & & $\begin{array}{l}\text { Authors emphasize the importance of the role of } \\
\text { dentists in facilitating the behavior of } \\
\text { different treatment options through professional } \\
\text { advice and reinforcements, which would lead to the } \\
\text { integration of extrinsic behavior into an intrinsic } \\
\text { motivation. }\end{array}$ \\
\hline 3 & Newton et al (2015) & $\begin{array}{l}\text { Managing oral hygiene } \\
\text { as a risk factor for } \\
\text { periodontal disease: A } \\
\text { systematic review of } \\
\text { psychological approaches } \\
\text { to behavior change for } \\
\text { improved plaque control in } \\
\text { periodontal management }\end{array}$ & $\begin{array}{l}\text { Determine the effect of } \\
\quad \text { psychological } \\
\text { interventions on behavior } \\
\text { related to oral health }\end{array}$ & $\begin{array}{l}\text { Three studies with low risk of bias reported an } \\
\text { approach based on the motivational interview } \\
\text { (MI) to modify the behavior related to oral hygiene } \\
\text { of individuals with periodontal disease. Of the } 3 \\
\text { included studies, only one study reported significant } \\
\text { effects of the interview motivational at plaque levels. } \\
\text { The authors suggested these results may be due } \\
\text { to a single IM session being used and in very short } \\
\text { periods of time (approximately } 15 \text { minutes). }\end{array}$ \\
\hline 4 & Kay et al (2016) & $\begin{array}{l}\text { Motivational interviewing } \\
\text { in general dental practice: } \\
\text { A review of the evidence }\end{array}$ & $\begin{array}{l}\text { Evaluate the effectiveness of } \\
\text { the motivational } \\
\text { interview to be used in the } \\
\text { dental context }\end{array}$ & $\begin{array}{c}\text { Autors noted that } 5 \text { of } 8 \text { studies evidence } \\
\text { motivational interview had positive effects on oral } \\
\text { health behavior. }\end{array}$ \\
\hline 5 & $\begin{array}{c}\text { Kopp SL et al } \\
-2017\end{array}$ & $\begin{array}{l}\text { Motivational interviewing } \\
\text { as an adjunct to } \\
\text { periodontal therapy-A } \\
\text { systematic review }\end{array}$ & $\begin{array}{l}\text { Know the effects of the } \\
\text { motivational interview as a } \\
\text { complement in periodontal } \\
\text { therapy }\end{array}$ & $\begin{array}{l}\text { Of the } 5 \text { included studies, only } 3 \text { studies showed } \\
\text { positive effects of the motivational interview on } \\
\text { oral health. The remaining ones did not obtain } \\
\text { significant effects. However, they conclude that use } \\
\text { of the motivational interview as a complement } \\
\text { in periodontal therapy could help to reduce } \\
\text { peridontal parameters and act successfully on those } \\
\text { psychological factors related to the behavior of } \\
\text { individuals. }\end{array}$ \\
\hline
\end{tabular}

Evaluation Tools and Monitoring of the Patient's Motivation in Oral Maintenance Phases

Evaluation of the type of motivation presented by patients undergoing dental treatment is very important, since, as several studies have shown, if the change in behaviour with respect to oral health is not achieved in the course of dental treatment, no matter how effective a therapy may be, in the long term it will fall into failure. Intrinsic motivation is often assessed in a behavioural way in terms of activities that are pursued freely and, experimentally through self-report questionnaires that probe the reasons for their participation in activities, as well as specific affective states such as interest, curiosity and fun [14]. We show a series of tools that can be used to assess the intrinsic motivation of patients regarding oral health.

\section{DIMS-Dental Intrinsic Motivation Scale}

Syrjälä et al. [37] developed a scale to assess intrinsic dental motivation (DIM-S) in order to analyse motivation problems in dental care in a group of young middle-aged Finnish patients. The previously validated instrument consisted of a questionnaire of 15 items formulated to correspond to internal (intrinsic) or external (extrinsic) motivation in relation to dental care. The extreme internal response received a score of four and the extreme external response a score of one. The analysis of the scale revealed the following dimensions: responsibility versus non-independence, interest in preserving one's teeth as long as possible versus preference for tooth extraction, satisfaction with brushing teeth versus brushing for the good of others, and critical evaluation of diet versus improper diet with carbohydrates [37]. 
The DIMS was used in a recent study by Patanapu et al. (2019) where, through the implementation of the DIMS, they determined the effect of motivation on oral hygiene in young adults. The participants were instructed to express their opinion on a dichotomous scale of score 1 (agree) and score 2 (disagree). The total score ranged from 12 to 24 where the highest scores indicated that the students had an intrinsic motivation. A score of 18 was considered a limit and the score $<18$ indicated the extrinsic motivation.10

\section{DTMS-Motivation Scale in Dental Treatment}

DTMS measures autonomous and controlled motivations. This scale was created by Sripriya et al. [38] who made an adaptation of another scale to be able to use it in dentistry. The authors used DTMS to assess motivation in patients aged 18-55 undergoing periodontal treatment. The DTMS is composed of 15 items, of which 7 (Q no: 1, 2, 5, 7, 10, 13 and 15) evaluate the intrinsic motivation and 8 (Q no: 3, 4, 6, 8, 9, 11, 12 and 14) evaluate extrinsic motivation respectively. The answers are organized on a Likert scale of 1 to 5 that goes from "strongly disagree" to "strongly agree." The score of each dimension is obtained by the total sum of all the responses of the elements in each dimension. authors report that the DTMS has a good consistency and validity to be used [38].

\section{Basic Psychological Needs Satisfaction Scale}

This scale is used to assess the three basic psychological needs; autonomy, competence and social relationship. A psychological need is an energizing state that, if satisfied, leads to health and well-being, but if not satisfied, contributes to pathology and discomfort, Ryan and Deci [13] state that these needs are essential to cause intrinsic motivation in an individual [13].

Halvari et al. [15] evaluated the basic psychological needs in the dental clinic, using the "Satisfaction Scale of Basic Psychological Needs" in the exercise, which adapted to the domain of the dental clinic. It consists of 9 elements intended to measure the satisfaction of the 3 basic needs, with 3 elements each. The items are averaged to reflect the satisfaction of each need. The participants answer the questions following this root: when you are in dental treatment, how true or false are the following statements?, the answers are given on a scale that varies from nothing true "1" to very true "7" [15].

\section{TSRQ-Self-Regulation Questionnaire for Dental Treatment}

Self-Regulation for Treatment Questionnaire (TSRQ) has been used for the measurement of autonomous motivation. This instrument is related to the reasons why people perform or perform some healthy behaviour [12]. TSRQ has the purpose of measuring the degree to which a person's motivation towards a particular behaviour is relatively autonomous. TSRQ has been theoretically described and validated by means of invariance analysis, exploratory factor analysis and has an internal acceptable consistency $\alpha>0.73$. The instrument follows a Likerttype modality with 7 points ranging from "not at all true" to "very true" and generally responses to the items related to autonomy are averaged to form the reflection of autonomous motivation towards behaviour that is a matter of study. In summary, the instrument evaluates the autonomous reasons for the change that would account for the person's progression along the continuum towards the integration of the behaviour. The scale has 15 items: 6 evaluate autonomous motivation, 6 evaluate controlled motivation, and 3 evaluate motivation. Flórez et al. [12] assessed internal motivation towards dental behaviour using the TSRQ, modified the original questionnaire to assess the level of motivation of each participant to improve home care and compliance with the recommended intervals of periodontal maintenance. The questionnaire included 2 subscales that evaluate autonomous regulation ( 6 items) and controlled regulation (4 items) respectively [12].

\section{Conclusion}

Oral health requires a maintained personal self-care to prevent the most prevalent oral diseases, in other words, patient has a personal or inherent commitment in their health. Motivation has been highlighted as a key element to achieve it. Studies suggest that motivation can be presented intrinsically or extrinsically, each one has different effects on the behaviour of an individual for a given activity. Current evidence suggests a constant concern on the part of dental professionals in achieving intrinsic motivation in patients. According to studies, the most commonly used methods are oral health education, motivational interview or a combination of both, the latter being the one that currently has gained a lot of success achieving positive effects on oral health when it is performed in several sessions. We emphasize the importance of the motivational interview, which is a cognitive method that has been used in different areas of health, especially in those people who seek to promote healthy behaviours. For example: consumers of alcohol, tobacco or other drugs, diabetics, people with obesity, eating disorders or people with risk factors for various diseases. The motivational interview is structured in several stages in order to ensure that individuals take control of their health and be aware about prevention and everything required to maintain healthy life.

\section{Conflict of Interest}

Authors declare no conflict of interest. The authors for the present review article received no funding.

\section{References}

1. Samic P, Garrahan JP, Rodríguez DJ, Dackiewicz DN, Toer D (2014) La gestión hospitalaria centrada en el paciente The patient-Centred hospital management. Arch Argent Pediat 11(2): 55-58.

2. Martín Zurro, Cano Pérez \& Gené Badia (2016) Primary Care Compendium: Concepts, organization and clinical practice in Family Medicine. ( $4^{\text {th }}$ Edtn.) Compendio de Atención Primaria.

3. PE Petersen, S Kwan (2010) The $7^{\text {th }}$ WHO Global Conference on Health Promotion - towards integration of oral health. Community Dental Health 27: 129-136. 
4. Cascaes AM, Bielemann RM, Clark VL, Barros AJD (2014) Effectiveness of motivational interviewing at improving oral health: A systematic review. Rev Saude Publica 48: 142-153.

5. Gao X, Lo ECM, Kot SCC, Chan KCW (2014) Motivational Interviewing in Improving Oral Health: A Systematic Review of Randomized Controlled Trials. J Periodontol 85: 426-437.

6. Kopp SL, Ramseier CA, Ratka-Krüger P, Woelber JP (2017) Motivational interviewing as an adjunct to periodontal therapy-A systematic review. Front Psychol 8: 1-9.

7. Newton JT, Asimakopoulou K (2015) Managing oral hygiene as a risk factor for periodontal disease: A systematic review of psychological approaches to behaviour change for improved plaque control in periodontal management. J Clin Periodontol 42: S36-S46.

8. Brannon Linda, Jess Feist (2011) Health Psychology. Psicologia de la Salud.

9. Godard A, Dufour T, Jeanne S (2011) Application of self-regulation theory and motivational interview for improving oral hygiene: A randomized controlled trial. J Clin Periodontol 38: 1099-1105.

10. Patanapu Shiva Kumar, Dolar Doshi, Suhas Kulkarni, Padma Reddy, Srikanth Reddy AS (2019) Effect of motivation on oral hygiene and caries status among young adults in the city of Hyderabad. Indian J Dent Res 30: 15-20.

11. Simpson EH, Balsam PD (2016) The Behavioral Neuroscience of Motivation: An Overview of Concepts, Measures, and Translational Applications Eleanor. Curr Top Behav Neurosci 27: 1-12.

12. Flórez-Alarcón L, Castellanos-Morales CA (2012) Efectos de la entrevista motivacional sobre la motivación autónoma en jóvenes consumidores de alcohol. Rev Salud Pública 14: 69-85.

13. Ryan RM, Deci EL (2000) Self-Determination Theory and the Facilitation of Intrinsic Motivation, Social Development, and Well-Being. Am Psychol 55: 68-78.

14. Di Domenico SI, Ryan RM (2017) The Emerging Neuroscience of Intrinsic Motivation: A New Frontier in Self-Determination Research. Front Hum Neurosci 11: 1-14.

15. Halvari AEM, Halvari H, Bjørnebekk G, Deci EL (2010) Motivation and anxiety for dental treatment: Testing a self-determination theory model of oral self-care behaviour and dental clinic attendance. Motiv Emot 34: 15-33.

16. Syrjälä AM , Knuuttila ML, Syrjälä LK (1994) Obstacles to regular dental care related to extrinsic and intrinsic motivation. Community Dent Oral Epidemiol 22(4): 269-272.

17. Münster Halvari AE, Halvari H, Deci EL (2017) Attending and avoiding dental appointments: Do "bright" and "dark" motivational paths have a role? Int J Dent Hyg 16: 286-297.

18. Brand VS, Bray KK, Macneill S, Catley D, Williams K (2013) Impact of single-session motivational interviewing on clinical outcomes following periodontal maintenance therapy. Int J Dent Hyg 11: 134-141.

19. Soldani FA, Young L, Jones K, Walsh T, Clarkson JE (2018) One-to-one oral hygiene advice provided in a dental setting for oral health. Cochrane Database Syst Rev.

20. Sala E, García P (2013) Odontología preventiva y comunitaria- principios, métodos y aplicaciones. Odontol. Prev. e comunitaria- principios, métodos y Apl.

21. Toassi RFC, Petry PC (2002) Motivation on plaque control and gingival bleeding in school children. Rev. Saude Publica 36: 634-637.
22. Ay ZY, Sayin MO, Ozat Y, Goster T, Atilla AO, et al. (2007) Appropriate oral hygiene motivation method for patients with fixed appliances. Angle Orthod. 77: 1085-1089.

23. Marini I, Bortolotti F, Incerti Parenti S, Gatto MR, Alessandri Bonetti G (2014) Combined effects of repeated oral hygiene motivation and type of toothbrush on orthodontic patients: A blind randomized clinical trial. Angle Orthod. 84: 896-901.

24. Huang J, Yao Y, Jiang J, Li C (2018) Effects of motivational methods on oral hygiene of orthodontic patients. Medicine (Baltimore) 97: e13182.

25. Weinstein P, Harrison R, Benton T (2004) Motivating parents to prevent caries in their young children: One-year findings. J Am Dent Assoc 135: 731-738.

26. Wu L, Gao X, Lo ECM, Ho SMY, McGrath C, et al. (2017) Motivational Interviewing to Promote Oral Health in Adolescents. J Adolesc Heal 61: 378-384.

27. Burke BL, Arkowitz H, Menchola M (2003) The efficacy of motivational interviewing: A meta-analysis of controlled clinical trials. J Consult Clin Psychol 71: 843-861.

28. Gao X, Lo EC, McGrath C, Ho SM (2013) Innovative interventions to promote positive dental health behaviors and prevent dental caries in preschool children: Study protocol for a randomized controlled trial. Trials 14: 1-8.

29. Batliner T, Fehringer KA, Tiwari T, Henderson WG, Wilson A (2014) Motivational interviewing with American Indian mothers to prevent early childhood caries: Study design and methodology of a randomized control trial. Trials 15: 1-8.

30. Ismail AI, Ondersma S, Willem Jedele JM, Little RJ, Lepkowski JM (2011) Evaluation of a brief tailored motivational intervention to prevent early childhood caries. Community Dent. Oral Epidemiol 39: 433-448.

31. Gillam DG, Yusuf H (2019) Brief Motivational Interviewing in dental practice. Dent J 7: 1-9.

32. Kay EJ, Vascott D, Hocking A, Nield H (2016) Motivational interviewing in general dental practice: A review of the evidence. Br Dent J 221: 785-791.

33. Harrison R, Veronneau J, Leroux B (2010) Design and implementation of a dental caries prevention trial in remote Canadian Aboriginal communities. Trials 11: 1-9.

34. Naidu R, Nunn J, Irwin JD (2015) The effect of motivational interviewing on oral healthcare knowledge, attitudes and behaviour of parents and caregivers of preschool children: An exploratory cluster randomised controlled study. BMC Oral Health 15: 1-15.

35. Woelber JP, Spann Aloge N, Hanna G, Fabry G, Frick K, et al. (2016) Training of Dental Professionals in Motivational Interviewing can Heighten Interdental Cleaning Self-Efficacy in Periodontal Patients. Front Psychol 7: 1-9.

36. Stenman J, Lundgren J, Wennström JL, Ericsson JS, Abrahamsson KH (2012) A single session of motivational interviewing as an additive means to improve adherence in periodontal infection control: A randomized controlled trial. J Clin Periodontol 39: 947-954.

37. Syrjälä AM, Knuuttila ML (1992) Intrinsic motivation in dental care. Community Dent Oral Epidemiol 20: 333-338.

38. Nagarajan S (2014) Motivation in Periodontal Therapy: Assessment Using Novel Dental Treatment Motivation Scale (DTMS). Dentistry 04. 
(C) Commons Attribution 4.0 License BY DOI: 10.19080/PBSIJ.2019.13.555870
Your next submission with Juniper Publishers will reach you the below assets

- Quality Editorial service

- Swift Peer Review

- Reprints availability

- E-prints Service

- Manuscript Podcast for convenient understanding

- Global attainment for your research

- Manuscript accessibility in different formats

( Pdf, E-pub, Full Text, Audio)

- Unceasing customer service

Track the below URL for one-step submission https://juniperpublishers.com/online-submission.php 